\title{
PENGARUH TUTUPAN VEGETASI TERHADAP LAJU SEDIMENTASI DI GUMUK PASIR PARANGTRITIS
}

\author{
Sri Haryanti P, Sutanto T.P \\ Fakultas Teknologi Sumber Daya Alam \\ sriharyanti@ity.ac.id,sutanto0612@ity.ac.id
}

\begin{abstract}
ABSTRAK
Gumuk pasir Parangtritis merupakan salah satu bentukan bentang alam eolian berupa bukit, gundukan atau punggungan yang berasal dari penumpukan pasir yang tertiup angin. Gumuk pasir ini telah mengalami tekanan yang sangat tinggi akibat dari aktivitas manusia, sebagai akibatnya, perkembangan dan fungsi dari gumuk pasir ini berkurang. Fungsi ekologis Gumuk pasir antara lain mencegah terjadinya peresapan air laut (intrusi) ke lapisan air tanah, mencegah abrasi, dan sebagai penghalang (barrier) pertama ketika terjadi bencana tsunami, mengingat Kabupaten Bantul termasuk wilayah rawan bencana alam gempa bumi dan tsunami. Perubahan kondisi ekologi terutama perubahan akibat interaksi manusia dengan lingkungan yang terus berkembang dari waktu ke waktu memiliki efek terhadap dinamika laju sedimentasi gumuk pasir.

Penelitian ini menitikberatkan pada pengumpulan dan pengolahan data primer. Data primer tersebut diambil secara berkala dan dilakukan pengolahan setelahnya. Data sedimentasi pasir diambil menggunakan patok ukur. Patok ukur ditempatkan pada 20 stasiun pengamatan. Penelitian ini bertujuan untuk mengetahui pengaruh tutupan terutama vegetasi terhadap dinamika laju sedimentasi gumuk pasir Parangtritis

Daerah dengan tutupan terbuka dan memiliki pergerakan angin yang tidak terhalang, cenderung memiliki tingkat erosi lebih tinggi dibandingkan dengan lokasi dengan tutupan lahan bervegetasi maupun terpengaruh oleh tingginya aktivitas manusia. Lokasi yang demikian cenderung mengalami sedimentasi lebih tinggi karena terhalangnya angin pembawa material
\end{abstract}

Kata Kunci : Gumuk Pasir Parangtritis, Tutupan Vegetasi, Laju Sedimentasi

\section{THE EFFECT OF VEGETATION COVER ON SEDIMENTATION RATE IN PARANGTRISTIS COASTAL $D U N E$}

\begin{abstract}
Parangtritis Coastal Dune is one of the coastal aeolian landform that in the form of a hill mound or ridge that comes from a buildup of sand blown by the wind. This sand dune has experienced a lot of pressure from anthropogenic activities, as the result, development and function of the sand dune has decreased. Ecological functions Sand dunes include preventing seepage of water (intrusion) into the groundwater layer, preventing abrasion, and as the first barrier (barrier) during a tsunami disaster, considering that Bantul Regency is an area prone to earthquakes and tsunami. Changes in ecological conditions, especially changes due to human
\end{abstract}


interactions with the environment that continue to evolve over time have an effect on the dynamics of the sand sedimentation rate.

This research focuses on the collection and processing of primary data. Primary data is taken periodically and is processed afterwards. Sand sedimentation data was taken using measuring stakes. Measurements are placed on 20 observation stations. This study aims to determine the effect of cover, especially vegetation on the dynamics of the sedimentation rate of Parangtritis Coastal Dunes.

Areas with open cover and have unobstructed wind movements tend to have higher erosion rates compared to locations with vegetated land cover or influence by high human activity. Such locations tend to experience higher sedimentation due to obstruction of material carrier winds

Keywods: Coastal Dunes Parangtritis, Vegetation Cover, Sedimentation Rate

\section{A. PENDAHULUAN}

Gumuk pasir merupakan salah satu bentukan bentang alam eolian berupa bukit, gundukan atau punggungan yang berasal dari penumpukan pasir yang tertiup angin. Di Indonesia, gumuk pasir berkembang di wilayah pantai Parangtritis. Gumuk Pasir Parangtritis dapat berkembang karena adanya suplai material dari Gunung Merapi, terbawa oleh aliran sungai dan proses marin, kemudian terbawa angin dan terendapkan karena terhalang oleh perbukitan di sebelah utara. Sunarto (2014), menyimpulkan bahwa ada sembilan faktor pembentuk gumuk pasir di kepesisiran yang meliputi: 1) adanya tiupan angin dari laut menuju ke pantai; 2) adanya koridor angin (wind corridor) atau lorong angin alami (wind tunnel); 3) adanya pasokan material pasir; 4) material berbentuk lepas-lepas; 5) morfologi gisik; 6) kelerengan gisik; 7) lebar gisik; 8) julat pasut; 9) penghalang angin.
Gumuk pasir merupakan bentuk lahan yang unik dan langka di wilayah pesisir. Selain proses aeolian, menurut Martinez, et al. (2008) dalam Santosa (2015), pembentukan gumuk pasir juga dipengaruhi oleh kondisi fisik lingkungan berupa tipe pantai, pesisir yang terbuka luas menghadap lautan, serta tidak terdapat penghalang di bagian depannya.

\section{B. TINJAUAN PUSTAKA}

Material pasir yang menjadi bahan baku pembentukan gumuk pasir berasal dari hasil erupsi Gunungapi Berapi dan lapukan batuan. Material pasir tersebut selanjutnya dibawa oleh aliran Sungai menuju ke muara sungai. Kemudian material tersebut diangkut dan diendapkan di sepanjang pantai oleh gelombang. Material pasir halus atau material klastik dan lepas-lepas yang berada di sepanjang pantai terangkut secara kuat oleh angin musim tenggara ketika musim kemarau. Hal tersebut menyebabkan terjadinya proses 
pemindahan dan pengendapan pasir di atas beting gisik tua (Santosa, 2002). Proses ini dikenal dengan deflation process. Proses pembentukan gumuk pasir ini didukung oleh keberadaan lorong angin Parangtritis-Parangkusumo. Selain itu, keberadaan gawir sesar yang membentang dari utara-selatan di sebelah timur wilayah pesisir Parangtritis-Parangkusumo juga mempercepat proses pembentukan gumuk pasir ini (Santosa, 2015). Proses deflasi pasir pada berbagai tipe gumuk pasir berbeda tergantung pada faktor-faktor yang menyertainya yaitu kecepatan dan arah angin, kerapatan vegetasi dan pasokan material pasir.

Gumuk pasir memiliki fungsi ekologis yang penting antara lain mencegah terjadinya peresapan air laut (intrusi) ke lapisan air tanah, mencegah abrasi, dan sebagai penghalang (barrier) pertama ketika terjadi bencana tsunami, mengingat Kabupaten Bantul termasukwilayah rawan bencana alam gempa bumi dan tsunami. Gumuk pasir memiliki berbagaipotensi antara lain pariwisata, olahraga, pertanian, edukasi, ekonomi, konservasi, riset,sosial dan budaya (Sungkowo et al. 2014).

Secara alami, Gumuk Pasir Parangtritis memiliki tutupan alami berupa semak dengan tutupan yang tidak banyak, tetapi mulai tahun 80an, mulai dilakukan penghijauan (Nuraini et al., 2016), penghijauan tersebut merupakan upaya dari Dinas Pertanian dan Kehutanan Kabupaten Bantul untuk melindungi lahan warga dari pasir dan uap air asin (Khatimah et al., 2017). Kidd (2001) menjelaskan bahwa vegetasi penutup merupakan faktor yang sangat berpengaruh terhadap perubahan morfologi gumuk pasir. Hal ini dikarenakan kecepatan angin akan tertahan oleh vegetasi tersebut, sehingga material deposisi terperangkap pada muka vegetasi dan angin mengalami percepataan penurunan (loncatan angin) membentuk angin turbulen di belakang vegetasi.

Perubahan kondisi ekologi terutama perubahan akibat interaksi manusia dengan lingkungan yang terus berkembang dari waktu ke waktu memiliki efek terhadap dinamika laju sedimentasi gumuk pasir. Penelitian ini bertujuan untuk mengetahui pengaruh tutupan terutama vegetasi terhadap dinamika sedimentasi Gumuk Pasir Parangtritis

\section{METODE PENELITIAN}

Penelitian ini difokuskan pada pengumpulan dan pengolahan data primer. Data primer tersebut diambil secara berkala dan dilakukan pengolahan setelahnya. Data sedimentasi pasir diambil menggunakan patok ukur kayu dengan penanda ketinggian di salah satu sisinya. 
Stasiun pengamatan dengan patok pengamatan yang dipasang di lokasi berjumlah 20 buah dengan

sebaran dan pemilihan lokasi mempertimbangkan lahannya (Gambar 1).

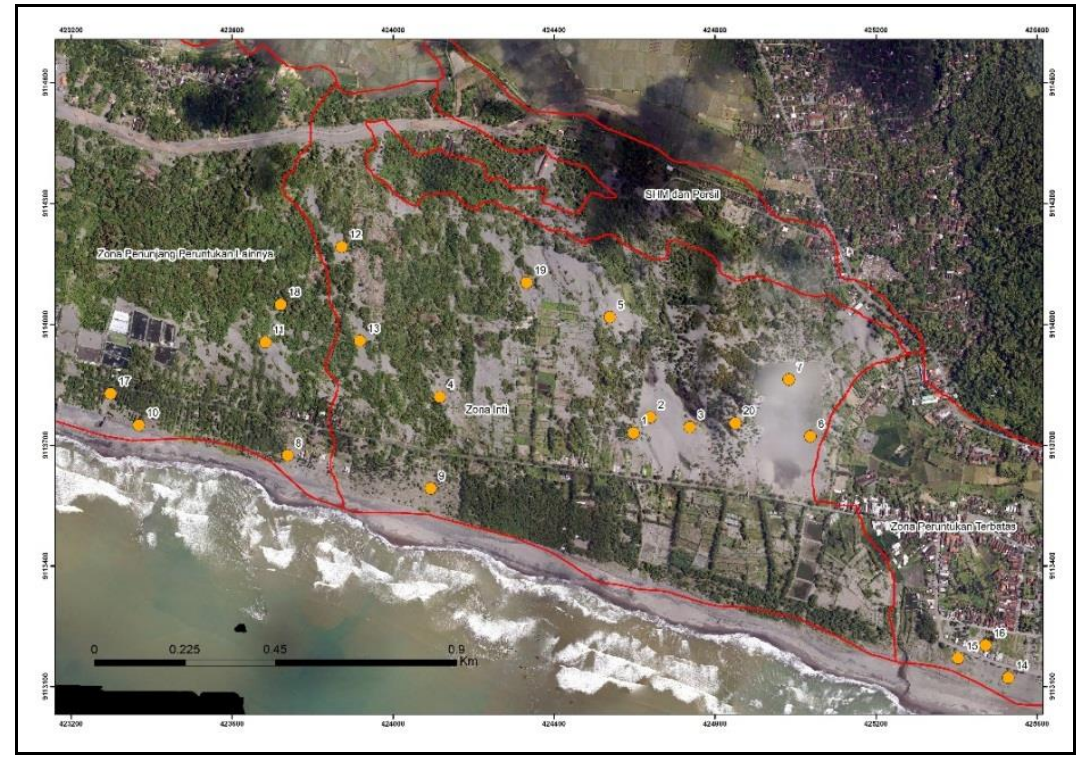

Gambar 1. Lokasi sebaran Patok

Patok kayu yang dipasang memiliki ukuran panjang $2 \mathrm{~m}$, dan ditanam dengan kedalaman antara 50 s.d. $100 \mathrm{~cm}$ untuk memastikan agar patok tidak goyah oleh angin (Gambar 2).

Pengamatan dilakukan dengan mencatat ketinggian pasir dan parameter cuaca di titik stasiun

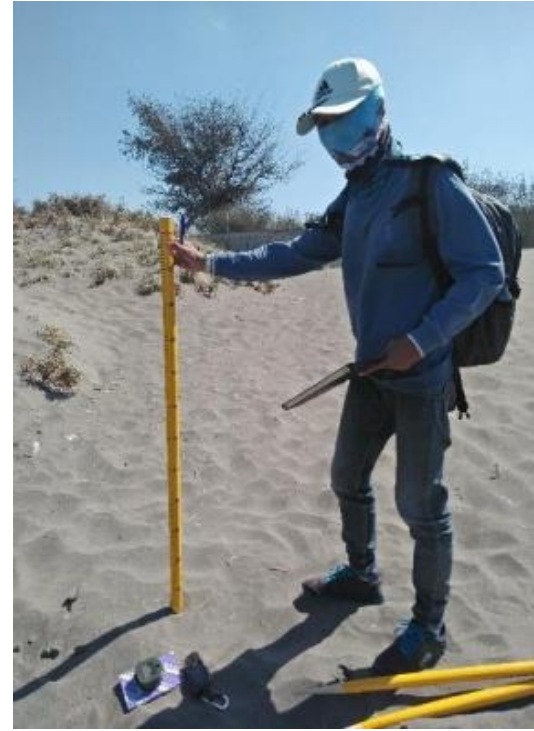

Gambar 2. Patok Kayu

Berdasarkan pengamatan ketinggian pasir di patok pada saat sebelumnya, dapat diketahui jumlah penambahan atau pengurangan ketinggian. Perbedaan ketinggian 
tersebut mengindikasikan adanya proses sedimentasi yang terjadi.

\section{HASIL DAN PEMBAHASAN Stasiun Pengamatan}

Penempatan stasiun

pengamatan ditempat di 20 lokasi yang tersebar di 3 zona Kawasan Gumuk Pasir Parangtritis dengan rincian sebagai berikut:

- Zona 1 , Zona Inti seluas 141,1 ha ditempatkan sebanyak 12 buah yaitu stasiun no: $1,2,3,4,5,6,7$, 9,12,13,19,20)

- Zona 2, Zona Peruntukan Terbatas seluas 95,3 ha ditempatkan sebanyak 3 buah yaitu stasiun no: 14,15,16,

- Zona 5, Zona Peruntukan Lainnya seluas 176,4 ha ditempatkan sebanyak 5 buah yaitu stasiun no : $8,10,11,17,18$

Kondisi sekitar Stasiun dapat dilihat pada tabel 1

\section{Kondisi Pada Sekitar Stasiun Pengamatan}

Lokasi peletakan stasiun pengamatan mempertimbangkan tutupan lahan dan bentukan pola sedimentasi. Sebagian besar patok diletakkan dibagian wind tunnel atau lorong angin dimana sirkulasi angin paling tinggi terjadi. Tutupan lahan yang dipertimbangkan adalah adanya halangan angin oleh bentukan baik berupa vegetasi maupun hasil proses antropogenik seperti yang ada di kawasan wisata gumuk pasir. Kondisi sekitar stasiun pengamatan terdapat lokasi terbuka tanpa halangan, terhalang semak dan terhalang vegetasi keras. Kondisi Terhalang yang dimaskudkan disini adalah terhalangnya angin dari arah datangnya karena adanya tutupan vegetasi maupun aktivitas manusia

Monitoring sedimen sudah dilakukan sebanyak tujuh kali dengan interval yang berbeda selama kurun waktu 3 bulan.

Tabel 1. Kondisi sekitar stasiun pengamatan

\begin{tabular}{|c|c|c|c|}
\hline 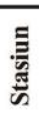 & $\begin{array}{l}\text { Kondisi } \\
\text { sekitar } \\
\text { stasiun }\end{array}$ & 㫊 & $\begin{array}{l}\text { Kondisi } \\
\text { sekitar } \\
\text { stasiun }\end{array}$ \\
\hline 1 & $\begin{array}{l}\text { Terhalang, } \\
\text { Wisata, } \\
\text { vegetasi keras }\end{array}$ & 11 & Terbuka \\
\hline 2 & $\begin{array}{l}\text { Wisata, } \\
\text { terbuka }\end{array}$ & 12 & $\begin{array}{l}\text { Terhalang } \\
\text { vegetasi di } \\
\text { depan }\end{array}$ \\
\hline 3 & $\begin{array}{l}\text { Wisata, } \\
\text { terbuka }\end{array}$ & 13 & $\begin{array}{l}\text { Terhalang } \\
\text { vegetasi di } \\
\text { depan }\end{array}$ \\
\hline 4 & $\begin{array}{l}\text { Terhalang, } \\
\text { semak }\end{array}$ & 14 & Terbuka \\
\hline 5 & $\begin{array}{l}\text { Terhalang, } \\
\text { semak }\end{array}$ & 15 & Terbuka \\
\hline 6 & $\begin{array}{l}\text { Wisata, } \\
\text { semak }\end{array}$ & 16 & $\begin{array}{l}\text { Dekat warung, } \\
\text { semak }\end{array}$ \\
\hline 7 & $\begin{array}{l}\text { Dekat } \\
\text { pertanian, } \\
\text { vegetasi } \\
\text { keras, } \\
\text { terhalang, } \\
\text { seresah }\end{array}$ & 17 & $\begin{array}{l}\text { Terbuka di } \\
\text { depan. } \\
\text { Dilingkupi } \\
\text { vegetasi }\end{array}$ \\
\hline 8 & $\begin{array}{l}\text { Pertanian, } \\
\text { Terbuka }\end{array}$ & 18 & $\begin{array}{l}\text { Terhalang } \\
\text { vegetasi }\end{array}$ \\
\hline 9 & $\begin{array}{l}\text { Terbuka, } \\
\text { semak }\end{array}$ & 19 & $\begin{array}{l}\text { Terbuka, } \\
\text { semak }\end{array}$ \\
\hline 10 & Terbuka & 20 & $\begin{array}{l}\text { Terhalang, } \\
\text { semak }\end{array}$ \\
\hline
\end{tabular}

$\mathrm{Su}$

mber: Data Primer, 2018

\section{Rata-rata Laju Sedimentasi}

Berdasarkan data yang terkumpul diperoleh hasil seperti pada (tabel 2). Data masih sangat terbatas, sehingga masih perlu dilakukan pengumpulan data 
tambahan untuk seri panjang agar nampak pola secara spasial dari sedimentasi yang ada. Direncanakan, data akan dikumpulkan hingga minimal 2 tahun, sehingga akan diperoleh 2 kali musim hujan dan kemarau. Berdasarkan hasil pengukuran angin diperoleh hasil bahwa secara umum angin berhembus ke arah barat laut (Gambar 3).

Tabel 2. Rata-rata sedimentasi tiap titik pengamatan

\begin{tabular}{|c|c|c|c|}
\hline $\begin{array}{l}\equiv \\
\text { 营 } \\
\text { 芯 }\end{array}$ & 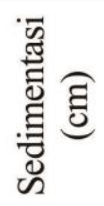 &  & 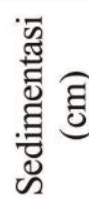 \\
\hline 16 & 1,83 & 4 & 0,92 \\
\hline 18 & 1,67 & 2 & 0,83 \\
\hline 10 & 1,50 & 8 & 0,83 \\
\hline 3 & 1,30 & 11 & 0,83 \\
\hline 12 & 1,17 & 13 & 0,80 \\
\hline 6 & 1,13 & 5 & 0,58 \\
\hline 17 & 1,08 & 7 & 0,58 \\
\hline 19 & 1,08 & 9 & 0,42 \\
\hline 1 & 1,00 & 14 & - \\
\hline 20 & 1,00 & 15 & - \\
\hline
\end{tabular}

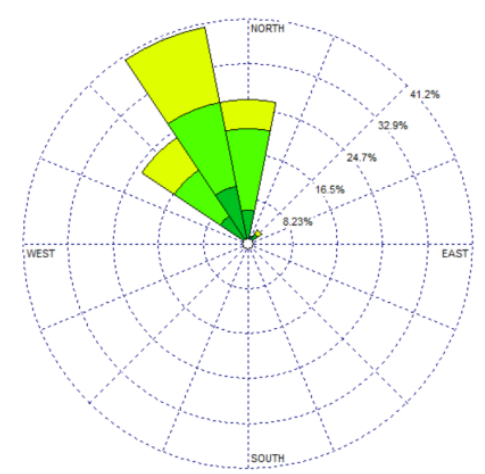

Gambar 3. Mawar Angin untuk waktu kajian di lokasi kajian
Dari hasil pengamatan dan pengolahan data terlihat bahwa titiktitik yang berpenghalang dengan laju sedimentasi dan erosi rendah adalah titik 1, 4, 5, 13, 19 dan 20. Jika dikalkulasikan antara erosi dan sedimentasi, maka diketahui titik mana yang mengalami surplus sedimen dan titik mana yang defisit. Titik-titik yang mengalami surplus sedimen adalah titik $1,4,5,9,11,12$, 18 dan 19, sedangkan titik defisit sedimen adalah 2, 6, 7, 8, 10, 13, 16 dan 17.

Kondisi surplus maupun defisit ditentukan dari kondisi tutupan lahan yang ada. Kondisi tutupan lahan juga mempengaruhi pergerakan angin lokal yang ada di suatu wilayah. Titik-titik yang mengalami surplus dipengaruhi oleh hambatan angin oleh vegetasi, sehingga pasir berhenti di titik tersebut, sedangkan titik dengan kondisi defisit, disebabkan karena terbukanya muka lokasi terhadap arah datangnya angin.

Daerah dengan sedimentasi tinggi seperti stasiun 16, memiliki kondisi terhalang baik oleh bangunan semi permanen di bagian yang menghadap laut, searah dengan arah angin, dan semak di sisi yang lain. Sedangkan titik dengan sedimentasi rendah, seperti stasiun no 9, berada dekat dengan pantai. Titik no 9 merupakan zona transport pasir, sehingga hembusan angin dengan tenaga yang besar dari arah laut, didukung dengan minimnya 
penghalang di titik stasiun, menyebabkan angin dengan leluasa membawa material, sehingga mengakibatkan minimnya sedimentasi di stasiun pengamatan ini.

\section{KESIMPULAN}

Sedimentasi di Gumuk Pasir Parangtritis dipengaruhi oleh tutupan lahannya. Secara umum, tutupan lahan tersebut akan berpengaruh terhadap pergerakan angin lokal yang mampu mengakibatkan terjadinya erosi maupun sedimentasi pasir. Daerah dengan tutupan terbuka dan memiliki pergerakan angin yang tidak terhalang, cenderung memiliki tingkat erosi lebih tinggi dibandingkan dengan lokasi dengan tutupan lahan bervegetasi maupun terpengaruh oleh tingginya aktivitas manusia. Lokasi yang demikian cenderung mengalami sedimentasi lebih tinggi karena terhalangnya angin pembawa material.

\section{SARAN}

Pengamatan akan jauh lebih baik apabila ditambah waktunya untuk satu tahun kedepan untuk menghasilkan data yang lebih valid. Perlu kajian lebih lanjut mengenai jenis dan karakteristik vegetasi tutupan dan pengaruhnya terhadap sedimentasi

\section{UCAPAN TERIMA KASIH}

Terima kasih kami ucapkan kepada Kementerian Riset dan
Teknologi yang telah membiayai penelitian ini melalui skema Penelitian Dosen Pemula tahun 2018. Terima kasih pula kami ucapkan kepada LPPM Institut Teknologi Yogyakarta yang mendukung terselesaikannya kegiatan ini. Terima kasih pula kepada Pihak Parangtritis Geomaritime Science Park yang telah memberikan citra dan data iklim untuk pelaksanaan penelitian ini. Tak lupa terima kasih diucapkan kepada mahasiswa yang membantu pengumpulan data di penelitian ini.

\section{DAFTAR PUSTAKA}

Khatimah, K., Syaukat, Y., \& Ismail, A. (2018). Analisis Penilaian Ekonomi Gumuk Pasir Parangtritis di Kecamatan Kretek , Kabupaten Bantul , DIY, 17(2), 138-150.

Kidd, R. (2001). Coastal Dune Management a Manual of Coastal Dune Management and Rehabilitation Techniques. Newcastle: NSW Goverment.

Nuraini, F. , Sunarto, \& Santosa, L., W., (2016). Pengaruh vegetasi terhadap dinamika perkembangan gumuk pasir di Pesisir Parangkusumo. Geomedia, 14(2), 1-11.

Santosa, L.W. (2015). Keistimewaan Yogyakarta dari Sudut Pandang Geomorfologi. Yogyakarta: UGM Press 
Santosa, L.W. 2002. Hydro-chemical of The Unconfined Aquifer at The Kulonprogo Coastal Area. Journal on Environmental Chemistry and Toxicology, Vol.1, No.1, Mei 2002

Sungkowo, A., E. Muryani, dan F.A. Astuti. (2014). Penilaian Relatif Ekosistem Gumuk Pasir Sebagai Kawasan Konservasi atau Pertambangan di Pantai Selatan. Makalah diprensentasikan pada Seminar Nasional Kebumian - IX Fakultas Teknlogi Mineral UPN Veteran Yogyakarta, Yogyakarta 4-5 Desember 2014

Sunarto. (2014). Geomorfologi dan Kontribusinya dalam Pelestarian Pesisir Bergumuk Pasir Aeolian dari Ancaman Agrogenik dan Urbanogenik. Pidato pengukuhan Jabatan Guru Besar, pada Fakultas Geografi, Universitas Gadjah Mada. Universitas GadjahMada 2 April 2014. 